\title{
Chest Drain Insertion-Made Easy with Gum Bougie
}

\author{
Sanjeev Arya ${ }^{*} \mathbb{D}$, Shantanu Belwal $^{1}$, Puneet Tyagi $^{2}$ \\ ${ }^{1}$ Medical Intensive Care Unit, Max Super Speciality Hospital, Dehradun, India \\ ${ }^{2}$ Max Super Speciality Hospital, Dehradun, India \\ Email: sanjeev.arya@hotmail.co.uk, shantanu.belwal@maxhealthcare.com, puneet.tyagi@maxhealthcare.com
}

How to cite this paper: Arya, S., Belwal, S. and Tyagi, P. (2019) Chest Drain Insertion-Made Easy with Gum Bougie. Case Reports in Clinical Medicine, 8, 275-280. https://doi.org/10.4236/crcm.2019.810033

Received: October 11, 2019

Accepted: October 27, 2019

Published: October 30, 2019

Copyright $\odot 2019$ by author(s) and Scientific Research Publishing Inc. This work is licensed under the Creative Commons Attribution International License (CC BY 4.0).

http://creativecommons.org/licenses/by/4.0/

\begin{abstract}
Background: Surgical Chest drain insertion is a lifesaving procedure. It requires skills and experience towards its prompt insertion. Quite often there is delay or failure caused in its insertion due to excessive fat and loose skin in the axillary area while using the conventional methods. Numerous guidelines exist advising its safe placement, but mishaps still occur, as reported multiple times, while placing the chest drain. In addition to this, a delay or failure of its successful insertion can lead to disastrous consequences. Case: We would like to share, with fellow readers, a novel technique which we used in placing a surgical chest drain successfully. We used a gum bougie to guide the chest drain into the pleural cavity instead of using metal trocar, stellate or long forceps. Conclusion: By using this method, we experienced that not only it reduced the amount of time taken for the procedure, but it also had positive impact on the ease of insertion without fear of causing damage to internal organs, which ultimately boosted the operator's confidence.
\end{abstract}

\section{Keywords}

Surgical, Chest, Drain, Insertion, Seldinger, Railroad, Gum, Bougie, Pneumothorax, Obese

\section{Background}

Surgical chest drain insertion is often a lifesaving procedure required to treat pneumothorax and haemothorax [1] [2] [3]. Surgical chest drains are also used frequently in Emergency Rooms and Intensive Care Units to treat massive pleural effusions and empyema [4].

Numerous guidelines have been published regarding its indications and safe placement, but mishaps still happen due to the complexities of the procedure 
specially when it is a blind technique [5]-[10].

A prompt placement of surgical chest drain warrants good skills and experience. A delay or technique failure which includes its wrong placement often leads to disastrous consequences. And for these reasons often, the intensivists depend on their colleague surgeons to insert one [11] [12] [13] [14].

Using "conventional technique" which includes narrow bore pigtail tube insertion or a wider bore tube insertion using pointed trocar, stylet or forceps can lead to accidental puncturing of lung, liver and the heart [15] [16] [17] [18] [19].

Many at times, the reason behind the delay and procedure failure are caused by presence of excessive subcutaneous fat with looseness of skin in and around the axillary area specially seen in obese and fragile patients [20] [21].

Often, while putting a surgical chest drain, the operator loses track of the tunnel which is made by dissecting the subcutaneous tissue and muscle fibres to gain access to pleural cavity. The procedure becomes even more difficult as the operator has significant time constraint on him or her.

To avoid the hurdles as mentioned above, we have devised an innovative technique of "Surgical Chest Drain Insertion" using "Railroad Technique" which we would like to share with the readers.

\section{Case}

A 55-year-old male with previous history of COPD (chronic obstructive pulmonary disease), arrived at Emergency Department, in the early hours, with sudden shortness of breath. Chest auscultation suggested no air entry on the right side, which was diagnosed as large right sided pneumothorax with the help of X-Ray chest. Patient was a known case of COPD (Chronic obstructive pulmonary disease) and an ex-smoker. Patient was diagnosed with COPD 10 years ago and left smoking 5 years after the diagnosis. He is prescribed steroids and antibiotics when he gets admitted with exacerbation of COPD, otherwise he takes regular nebulisations at home.

\section{Indication and Procedure}

A decision was made to place a surgical chest drain to treat pneumothorax. After the skin incision, blunt dissection of facia, subcutaneous fat and spreading of muscle fibres was done using blunt tip forceps until pleural space was accessed.

Thereafter we followed the track with little finger and swiped the finger $360^{\circ}$ along parietal pleura. Thereafter alongside the finger, a "Gum Bougie" with "atraumatic end first" was slipped into the pleural cavity for about 10 centimeters at an angle of 30 Degree to skin. It was decided if the bougie does not glide in smoothly the procedure would be abandoned (Figure 1).

In our experience we could direct the tip of gum bougie towards the apex of thoracic cavity over which a 16 French surgical chest drain (Flexo Cath-Thoracic Drainage Catheter, By Romsons India) was gently advanced and the "gum bougie" was withdrawn and the chest drain was connected immediately to an 
"under water seal" container and the chest drain was fixed to skin at 10 inches (Figure 2 and Figure 3).

$\mathrm{X}$-Ray chest taken after completion of procedure confirmed the placement of chest drain in desired position. It also showed resolution of pneumothorax (Figure 4).

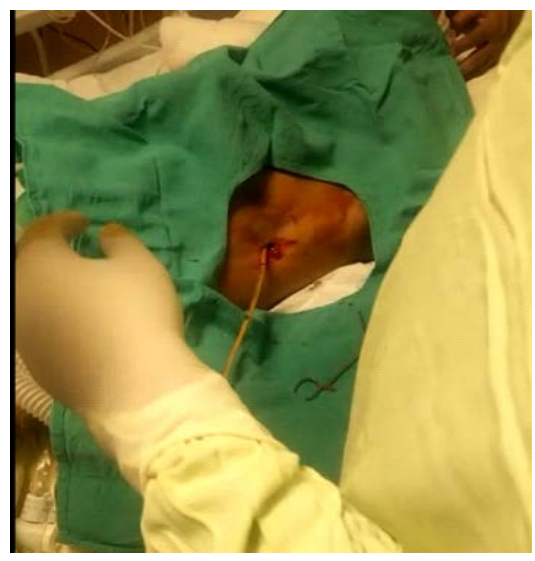

Figure 1. Insertion of Gum Bougie through the surgically created tunnel.

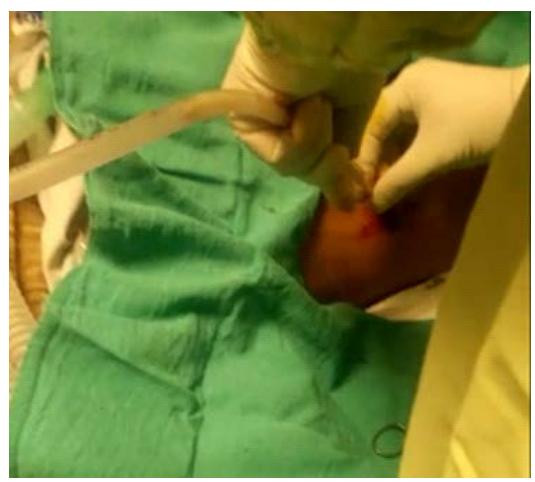

Figure 2. Threading of Surgical drain over the Gum Bougie.

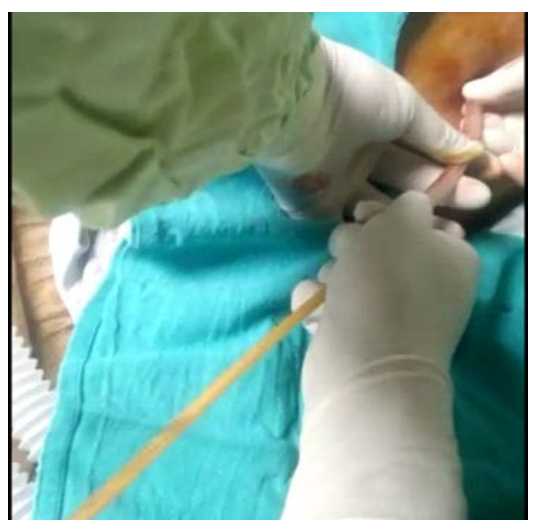

Figure 3. Pushing drain to the desired deapth and gradual removal of the Gum Bougie. 


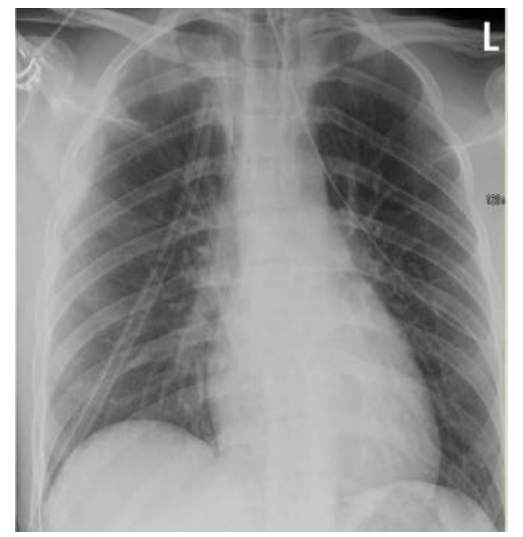

Figure 4. X Ray chest done after the placement of chest drain.

\section{Conclusions}

Very often surgical chest drain placement demands high level of expertise and promptness for its safe and right insertion.

Using the Railroad technique with the help of a gum bougie, as described above, the operators would experience that they are placing chest drains more easily as compared to using the conventional methods. They would also place chest drains more confidently in correct place and position.

\section{Limitations and Future Perspective}

Although the described technique was used successfully in first attempt and a couple of times thereafter, mainly in patients with pneumothorax, it would be worth using this technique (Chest drain insertion using a gum bougie) in patients who present with Pleural effusion, hemothorax and pyothorax as well.

It is also recommended to run a RCT (randomized control trial) to compare the advantages and disadvantages of this technique (Chest drain insertion using a gum bougie) with other "conventional techniques" of chest drain insertion.

\section{Declarations}

- Ethics approval and consent to participate was obtained from Max Healthcare's Institutional Ethics Committee (EIC) on $13^{\text {th }}$ Sept'19. Ref No: TS/MSSH/DDN/MHIL/ANAESTHESIA/IEC/19-02.

- Written and informed Consent for publication of manuscript, information about the patient and publishing Figures 1-4 was taken from the patient. Consent for publication was also obtained from the institution: Max Super Speciality Hospital, Dehradun, India.

- The consent form is held in the patients' clinical notes and is available for review by the Editor-in-Chief.

- The Institutional Ethics committee's approval and consent for publication is available for review by Editor-in-Chief.

- Availability of data and materials: NA. 
- No direct or indirect Funding was involved.

- Authors' contributions: All authors read and approved the final manuscript. SA performed the procedure, SB also scrubbed and helped during the procedure. PT supervised the procedure.

\section{Acknowledgements}

Special thanks to Maj. Rahul Prashad (Medical Superintendent), Max Super Speciality Hospital, Dehradun, for his advice on manuscript preparation, guidance and valuable inputs.

\section{Conflicts of Interest}

The authors declare no conflicts of interest regarding the publication of this paper.

\section{References}

[1] Henry, M., Arnold, T. and Harvey, J. (2003) BTS Guidelines for the Management of Spontaneous Pneumothorax. Thorax, 58, ii39-ii52.

https://doi.org/10.1136/thx.58.suppl_2.ii39

[2] Carson-Chahhoud, K.V., Wakai, A., Joseph, E.M., et al. (2017) Simple Aspiration versus Intercostal Tube Drainage for Primary Spontaneous Pneumothorax in Adults. Cochrane Database of Systematic Reviews. https://doi.org/10.1002/14651858.CD004479.pub3

[3] McConaghy, P.M. and Kennedy, N. (1995) Tension Pneumothorax Due to Intrapulmonary Placement of Intercostals Chest Drain. Anaesthesia and Intensive Care, 23, 496-498. https://doi.org/10.1177/0310057X9502300417

[4] Robert Shen, K., Bribriesco, A., Crabtree, T., et al. (2017) The American Association for Thoracic Surgery Consensus Guidelines for the Management of Empyema. The Journal of Thoracic and Cardiovascular Surgery, 153, e129-e146. https://doi.org/10.1016/j.jtcvs.2017.01.030

[5] Laws, D., Neville, E. and Duffy, J. (2003) BTS Guidelines for the Insertion of a Chest Drain. Thorax, 58, ii55-ii59.

[6] Porcel, J.M. and García-Gil, D. (2013) Emergencies in Pleural Diseases. Revista Clínica Española, 213, 242-250. https://doi.org/10.1016/j.rce.2012.11.006

[7] Maslove, D.M., Tze-Ming Chen, B., Wang, H., et al. (2011) The Diagnosis and Management of Pleural Effusions in the ICU. Journal of Intensive Care Medicine, 28, 24-36. https://doi.org/10.1177/0885066611403264

[8] Bristol, J.B. and Harvey, J.E. (1983) Safer Insertion of Pleural Drains. British Medical Journal, 286, 348-349. https://doi.org/10.1136/bmj.286.6362.348

[9] Firmin, R.K. and Tolhurst-Cleaver, C. (1980) Safe Intrapleural Drainage. Anaesthesia, 35, 79-80. https://doi.org/10.1111/j.1365-2044.1980.tb03751.x

[10] Cassivi, S.D., Deschamps, C. and Pastis, N.J. (2012) Chest Tube Insertion and Management. In: Spiro, S.G., Silvestri, G.A. and Agustí, A., Eds., Clinical Respiratory Medicine, 4th Edition, Chapter 72, Elsevier B.V., Amsterdam, 862-868. https://doi.org/10.1016/B978-1-4557-0792-8.00072-6

[11] Bailey, R.C. (2000) Complications of Tube Thoracostomy in Trauma. Emergency Medicine Journal, 17, 111-114. https://doi.org/10.1136/emj.17.2.111 
[12] Campbell, P., Neil, T. and Wake, P.N. (1989) Horner's Syndrome Caused by an Intercostal Chest Drain. Thorax, 44, 305-306. https://doi.org/10.1136/thx.44.4.305

[13] Mao, M., Hughes, R., Papadimos, T.J. and Stawicki, S. (2015) Complications of Chest Tubes. Current Opinion in Pulmonary Medicine, 21, 376-386. https://doi.org/10.1097/MCP.0000000000000169

[14] Shalli, S., Saeed, D., Fukamachi, K., et al. (2009) Chest Tube Selection in Cardiac and Thoracic Surgery: A Survey of Chest Tube-Related Complications and Their Management. Journal of Cardiac Surgery, 24, 503-509. https://doi.org/10.1111/j.1540-8191.2009.00905.x

[15] Abad, C. and Padron, A. (2002) Accidental Perforation of the Left Ventricle with a Chest Drain Tube. Texas Heart Institute Journal, 29, 143.

[16] Hesselink, D.A., Van Der Klooster, J.M., Bac, E.H., et al. (2001) Cardiac Tamponade Secondary to Chest Tube Placement. European Journal of Emergency Medicine, 8, 237-239. https://doi.org/10.1097/00063110-200109000-00014

[17] Yuncu, G., Aykanli, D., Yaldiz, S., et al. (1999) An Unusual Pulmonary Perforation Case after Chest Tube Placement. Acta Chirurgica Hungarica, 38, 231-233.

[18] Rashid, M.A., Wikstrom, T. and Ortenwall, P. (1998) Mediastinal Perforation and Contralateral Haemothorax by a Chest Tube. Thoracic Cardiovascular Surgery, 46, 375-376. https://doi.org/10.1055/s-2007-1013073

[19] Harris, A., Turkington, P.M. and O’Driscoll, B.R. (2008) Survey of Major Complications of Intercostal Chest Drain Insertion in the UK. Thorax, 63, A86.

[20] Britten, S. and Palmer, S.H. (1996) Chest Wall Thickness May Limit Adequate Drainage of Tension Pneumothorax by Needle Thoracocentesis. MJ Emergency Medicine Journal, 13, 426-427. https://doi.org/10.1136/emj.13.6.426

[21] El-Solh, A., Sikka, P., Bozkanat, E., Jaafar, W. and Davies, J. (2001) Morbid Obesity in the Medical ICU. Chest, 120, 1989-1997. https://doi.org/10.1378/chest.120.6.1989

\section{Abbreviations}

COPD: chronic obstructive pulmonary disease. 